\title{
O cuidado na doença de Alzheimer: as representações sociais dos cuidadores familiares
}

\author{
The care in Alzheimer's disease: social \\ representations of family caregivers
}

\section{Cinthia Filgueira Maciel Mendes}

Universidade do Estado do Pará. Centro de Ciências Biológicas

e da Saúde. Campus Enfermagem "Magalhães Barata". Guamá, PA, Brasil.

E-mail: cinthiafyløhotmail.com

\section{Anderson Lineu Siqueira dos Santos}

Universidade do Estado do Pará. Centro de Ciências Biológicas e da Saúde. Campus Enfermagem "Magalhães Barata". Guamá, PA, Brasil.

E-mail: anderson.lineuðhotmail.com

\section{Correspondência}

Avenida Sol Poente, n 2599, Cidade Nova. CEP: 68501670. Marabá, PA, Brasil.

\section{Resumo}

Este estudo aborda as representações de cuidadores familiares de idosos com Alzheimer considerando o cuidado à luz da Teoria das Representações Sociais. Objetiva observar e identificar as representações dos cuidadores familiares sobre o cuidado e analisar como influenciam em suas práticas de cuidado. É do tipo empírico, exploratório, qualiquantitativo e utiliza como método o Discurso do Sujeito Coletivo. Participaram 21 cuidadores familiares de idosos com Alzheimer, sendo $24 \%$ homens e $76 \%$ mulheres, com faixa etária de 32 a 69 anos. Sobre o suporte familiar, 57\% afirmaram possuir ajuda de parentes no cuidado com o idoso e $42 \%$ declararam cuidar sozinhos deles. Quanto à renda, $24 \%$ afirmaram que era confortável, 63\%, que era razoável. Quanto à ajuda de profissionais, $63 \%$ afirmaram não possuir qualquer tipo de ajuda em casa e $38 \%$ possuíam ajuda, mas frequentemente relacionada aos serviços domésticos. Emergiram as seguintes representações sociais: o cuidado como prisão; como missão; como desarmonia de identidades sociais e como gratidão. As representações atreladas às ideias de prisão e desarmonia de identidades acrescentam ansiedade, estresse e insegurança à vida dos cuidadores. Foram encontradas representações sobre o cuidado, sendo ao menos duas delas representações negativas, associando o cuidado às ideias de prisão e desarmonia de identidades sociais. Não foi possível alcançar de forma direta suas repercussões sobre a prática de cuidado pela ausência de observação da rotina de cuidado durante esta pesquisa.

Palavras-chave: Doença de Alzheimer; Cuidado; Família. 


\section{Abstract}

This study deals with the representations of family caregivers of seniors with Alzheimer considering care under the light of the Social Representations Theory. It aims to observe and identify the representations of family caregivers about care and analyze how they influence their care practices. This study is exploratory, empirical, quantitative and qualitative, using as a method of research the Discourse of the Collective Subject. Participants were 21 family caregivers of seniors with Alzheimer, $24 \%$ men and $76 \%$ women, aged $32-69$ years. About the support of the family, $57 \%$ of them reported having help from relatives in caring for the elderly and $42 \%$ did not have any help. About the income, $24 \%$ said it was comfortable, $63 \%$ said it was reasonable. About the help of professionals, $63 \%$ said they did not have any help at home, $38 \%$ had help, but mostly related to domestic services. The following social representations emerged: the care as prison; the care as mission; the care as disharmony of social identities and the care as gratitude. Representations linked to the ideas of prison and disharmony of social identity add anxiety, stress and insecurity of life of caregivers. This study found representations about the care of which at least two represented negative associations, comparing care with ideas of prison and disharmony of social identity. It was not possible to reach directly its repercussions on the care practice due to the absence of the care routine observation. Keywords: Alzheimer's disease; Care; Family.

\section{Introdução}

Mais de 46 milhões de pessoas no mundo vivem atualmente com algum tipo de demência, e a cada ano cerca de nove milhões de novos casos acontecem, segundo o World Alzheimer Report (ADI, 2015). A Doença de Alzheimer (DA) é a causa mais comum de demência, segundo a WHO (2012). Em 2009, o Brasil contava com uma população de cerca de 21 milhões de pessoas de 60 anos ou mais de idade, segundo a Pesquisa Nacional por Amostra de Domicílios - PNAD (Brasil, 2010). A incidência da DA é de 3\% dos indivíduos na faixa etária entre 60 e 65 anos, e cerca de 30\% nos indivíduos com oitenta anos ou mais, em âmbito mundial (Prince; Guerchet; Prina, 2013).

A demência é devastadora, não só para aqueles que sofrem, mas também para os seus cuidadores e famílias. Globalmente, é uma das principais causas de incapacidade e dependência entre os idosos. Na maioria dos países existe, de alguma forma, falta consciência e compreensão sobre a demência, o que provoca estigmas, barreiras ao diagnóstico e ao cuidado, e reflete sobre os cuidadores, familiares e sociedade, tanto do ponto de vista físico, como psicológico e econômico (OPAS, 2013, p. 2, tradução nossa).

A DA afeta a vida não apenas do idoso portador como também a de seus familiares. Quando se instala no seio familiar, compromete o seu relacionamento afetivo e causa desgastes físicos e emocionais, gerando problemas que podem ser assistidos pela equipe de saúde e, em especial, pela equipe de enfermagem (Figueiredo; Tonini, 2010).

A DA se caracteriza por processo degenerativo que acomete múltiplas funções corticais, incluindo memória, pensamento, compreensão e linguagem, sendo que a deficiência das habilidades cognitivas são comumente acompanhadas pela perda de controle emocional, do comportamento social e da motivação (OPAS, 2013). Sua neuropatologia envolve placas neuríticas e novelos neurofibrilares, caracterizados por alterações extracelulares com acumulação da proteína beta-amiloide, e seus sin- 
tomas iniciais incluem perturbações da memória, apatia e depressão (Freitas, 2015).

Para conceituar o cuidado vamos buscar a etimologia da palavra, que tem sua origem no latim cogitare (cogitar) (Cunha, 2010). Quanto ao significado, cuidar é imaginar, meditar, cogitar, aplicar a atenção, o pensamento e a imaginação (Ferreira, 2007).

Esse conceito se amplia para o social, podendo ser visualizado em suas várias dimensões. 0 cuidado pode ser visto como sentimento, atitude, necessidade humana, relação entre quem cuida e quem é cuidado, como conduta ética e profissão (Seguro et al., 20o8). Para Boff:

Cuidar é mais que um ato, é uma atitude. Portanto abrange mais que um momento de atenção, de zelo e desvelo. Representa uma atitude de ocupação, preocupação, de responsabilidade com o outro. [...] Sem o cuidado o ser humano deixa de ser humano. Se não recebe cuidado desde o nascimento até a morte, o ser humano desestrutura-se, definha, perde sentido e morre. [...] O grande desafio para o ser humano é combinar trabalho com cuidado. Eles não se opõem, mas se compõem. [...] O cuidar vive do amor primal, da ternura, da carícia, da compaixão, da convivialidade, da medida justa de todas as coisas (2011, p. 33-19o).

Segundo Boff (2011), o cuidado pode ter duas significações: pode ser entendido como preocupação, desinquietação, envolvimento afetivo ou atenção e solicitude, possuindo ainda ressonâncias que são entendidas como óticas diferentes do cuidado. Tais ressonâncias, o amor, a ternura, a compaixão, a cordialidade, a convivialidade, a medida justa e a carícia, são encontradas nas práticas do cuidado e juntas formam um cuidar completo e de qualidade.

Para compreender o cuidado dos familiares e as relações entre cuidadores e seus idosos com DA, utilizamos conceitos da Teoria das Representações Sociais, "entidades sociais" que dinamicamente estão em confronto e superação, e, uma vez criadas, adquirem vida própria, se modificando harmonicamente no curso da vida social, desaparecendo apenas para tornar a aparecer com nova aparência. "O poder e a claridade peculiares das representações - isto é, das representações sociais - deriva do sucesso com que elas controlam a realidade de hoje através da de ontem e da continuidade que isso pressupõe" (Moscovisci, 2011 p. 38).

Para Moscovici (2011), nossa percepção se encontra eclipsada, de tal modo que uma determinada classe de pessoas se torna invisível, quando de fato estão 'nos olhando de frente'. "[...] nós nunca conseguimos nenhuma informação que não tenha sido distorcida por representações 'superimpostas' aos objetos e às pessoas que lhes dão certa vaguidade e as fazem parcialmente inacessíveis" (Moscovisci, 2011, p.33).

Segundo Ximenes, Rico e Pedreira (2014) e Inouye, Pedrazzani e Pavarini (2010), existe despreparo entre as pessoas para lidar com a responsabilidade e sobrecarga que é cuidar de um idoso afetado por doenças demenciais, como o Alzheimer, pois em geral, existe um desconhecimento sobre a doença, sobre o como agir, como entender a pessoa afetada e seus próprios sentimentos, produzindo desgastes emocionais, físicos e psicológicos para o cuidador e a família por causa da longa duração do tratamento e da perda gradual das funções cognitivas do idoso, evoluindo para quadros de total dependência e exigindo cada vez mais a dedicação daqueles que com ele convivem.

Biondi, uma cuidadora de idoso com DA, da família, alerta sobre a necessidade dos cuidadores familiares de atenção dos profissionais da saúde quando afirma: "Nós, cuidadores de pessoas doentes, física ou mentalmente incapazes, ficamos com nossas vidas viradas de cabeça para baixo, literalmente. Por essa razão, necessitamos tanto da ajuda dos outros" (Biondi, 2009, p. 36).

A equipe de saúde, conhecendo os signos representativos que definem o mundo dos cuidadores familiares dos idosos com DA em relação ao cuidado, pode alcançar um padrão de assistência capaz de minimizar problemas de saúde advindos da realidade vivenciada por esse grupo social. "A enfermagem pode contribuir concretamente para o bem-estar psíquico e físico não só do idoso, mas também [...] das famílias que cuidam deles" (Figueiredo; Tonini, 2010, p. 27).

Portanto, partindo dessa perspectiva, elaboramos a seguintes questões norteadoras: Quais as 
representações sociais dos cuidadores familiares de idosos com DA sobre o cuidado? Qual a relação entre as representações sociais dos sujeitos deste estudo sobre o cuidado e suas práticas de cuidado de idosos com DA?

\section{Objetivos}

Geral: analisar as representações sociais dos cuidadores familiares de idosos com DA sobre o cuidado.

Específicos: identificar as representações sociais dos cuidadores familiares de idosos com DA sobre o cuidado; analisar como as representações sociais dos cuidadores familiares de idosos com DA repercutem em suas práticas de cuidado.

\section{Casuística e método}

Este estudo é do tipo empírico, exploratório, de abordagem qualiquantitativa e utiliza o método do Discurso do Sujeito Coletivo (DSC) que, segundo Lefevre e Lefevre (2012), vem permitindo significativas melhora na qualidade de pesquisas de atribuição social, uma vez que, por utilizar uma abordagem qualitativa e quantitativa, os resultados são passíveis de generalizações.

O local da pesquisa foi a Associação Brasileira de Alzheimer (ABRAz), no Município de Belém (PA). A ABRAz é uma entidade privada de natureza civil sem fins lucrativos. Integra familiares, cuidadores e profissionais oferecendo informações sobre o diagnóstico e tratamento e orientações sobre os aspectos cotidianos do acompanhamento da pessoa com DA. Nosso cenário de pesquisa foi composto pelos grupos da ABRAz (PA) que possuíam como público-alvo familiares cuidadores de Idosos com DA, já que deles foi retirada a amostra de nossa pesquisa.

Os sujeitos desta pesquisa foram os cuidadores familiares de idosos com DA. Os critérios de inclusão foram: a existência de algum grau de parentesco entre o cuidador e o idoso, seja de forma consanguínea ou legal (cônjuges com união estável), fazer parte dos grupos de apoio da ABRAz e aceitar participar da pesquisa. Foram realizadas 21 entrevistas.
A coleta de dados ocorreu seguindo apenas uma etapa de desenvolvimento: a solicitação da assinatura do Termo de Consentimento Livre e Esclarecido (TCLE) e entrevista individual gravada, utilizando um roteiro com a identificação dos sujeitos e perguntas abertas, buscando a "aquisição de depoimentos autênticos com vistas ao resgate do pensamento coletivo" (Lefèvre; Lefèvre, 2012, p. 49). Para garantir o anonimato, os sujeitos foram codificados de acordo com os seguintes pseudônimos: $\mathrm{C} 1, \mathrm{C} 2, \ldots \mathrm{Cn}$.

A análise dos dados seguiu as etapas previstas pelo método do DSC, como é apresentado a seguir: foi feita a transcrição integral do conteúdo das entrevistas; reconhecimento e recorte dos trechos dos depoimentos com maior conteúdo semântico, denominados Expressões-Chave (ECH); identificação das Ideias Centrais (IC) e Ancoragens (AC) dos depoimentos; nomeação de categorias e categorização das Expressões-Chave de acordo com semelhança de conteúdo semântico;

Formação do Discurso do Sujeito Coletivo com as ECHs agrupadas de acordo com as ICs e ACs. Foram avaliados os atributos quantitativos do DSC intensidade/força e amplitude.

Os resultados foram expressos em três partes. A pesquisa seguiu as diretrizes da Resolução 466/12 (Brasil, 2012), a qual assegura os direitos legais dos participantes da pesquisa, reconhecendo sua dignidade, autonomia e vulnerabilidade e assegurando sua vontade sob a forma de manifestação expressa livre e esclarecida de contribuir e permanecer ou não na pesquisa. 0 projeto de pesquisa foi submetido à apreciação do Comitê de Ética do Curso de Graduação em Enfermagem da Universidade do Estado do Pará e aprovado no início de setembro. Os riscos encontrados nesta pesquisa foram relacionados ao desconforto emocional envolvido no tema abordado e à quebra de anonimato. Enfatizamos nossa dedicação em preservar a integridade emocional dos participantes e os cuidados necessários - por exemplo, a utilização de pseudônimo para identificação dos participantes e proteção dos dados coletados, que foram utilizados com discrição e parcimônia e exclusivamente para obter os resultados desta pesquisa. Os benefícios 
relativos à pesquisa são obtidos de forma indireta pelos participantes, sendo uma contribuição para a qualificação da assistência voltada aos cuidadores, além da relevância para a comunidade científica e para a produção intelectual na área em questão, com resultados que direcionam a novas pesquisas em saúde e estabelecimento de planos assistenciais diferenciados para os cuidadores.

\section{Resultados}

\section{Indicadores Sociais dos Cuidadores Familiares}

Nesta pesquisa foram entrevistados 5 homens e 16 mulheres, reforçando a afirmação da literatura pesquisada: a mulher é quem mais desempenha o papel de cuidador (Camargo, 2010; Biolo; Portella, 2010). Porém, o homem não se isenta dessa atividade, já que 6o\% (n3) dos homens entrevistados desta pesquisa cuidam de seus parentes com DA sem apoio de outros familiares.

A faixa etária desses cuidadores varia entre $32 \mathrm{e}$ 69 anos, sendo que $47 \%$ (n1o) deles se encontravam na faixa etária de 40 a 59 anos, e 33\% (n7) tinham 60 anos ou mais - dado preocupante, já que são idosos que cuidam de outros idosos. São pessoas que já necessitam de cuidados para si, visto que o envelhecimento é um processo dinâmico e progressivo, no qual existem modificações morfológicas, funcionais, bioquímicas e psicológicas que determinam a perda da capacidade de adaptação do indivíduo ao meio ambiente, ocasionando uma maior vulnerabilidade e incidência de processos patológicos que terminam por levá-lo à morte (Santos; Júnior, 2014).

Sobre a renda familiar dos cuidadores, $72 \%$ (n15) disseram que a renda era razoável, 24\% (n5) disseram que a renda era confortável e 1 (um) sujeito disse que a renda era abaixo das necessidades. Apesar dessa informação, no discurso de muitos, inclusive daqueles que definiram a renda familiar como confortável, houve queixas sobre a falta de condições para cuidar do idoso com DA, para contratar profissionais para ajudar nas tarefas diárias do cuidar e do alto custo do tratamento por conta, principalmente, dos medicamentos e das fraldas geriátricas.
Dos sujeitos dessa pesquisa, 57\% (n12) possuem suporte familiar de filhos, irmãos ou companheiros e consideram que a rede familiar significa um apoio importante na tarefa de cuidar de um idoso com DA, enquanto que $42 \%$ (ng) são cuidadores familiares que não possuem ajuda dentro da família na tarefa diária de cuidados com o idoso, e o que se percebe é que, para estes, o cuidar de uma pessoa com DA se torna mais difícil por não haver uma rede familiar que os apoie, tornando as tensões familiares mais evidentes (Costa; Mourão; Gonçalves, 2014; Camargo, 2010).

Sobre a existência de ajuda profissional em casa, $62 \%$ (n13) afirmaram que não possuem qualquer tipo de ajuda e $38 \%$ (n8) disseram possuir ajuda profissional que, contudo, se refere mais a serviços domésticos do que aos relacionados ao cuidar. Entre os tipos de ajuda profissional que recebem, 4 pessoas ( $\left.\mathrm{C}_{2}, \mathrm{C} 4, \mathrm{C} 8, \mathrm{C} 12\right)$ se referiram a "empregadas domésticas", 1 pessoa (C18) se referiu a "diaristas”, 1 pessoa $\left(\mathrm{C}_{3}\right)$ se referiu a uma "babá" para ajudar com o idoso e duas outras ( $\mathrm{C} 1, \mathrm{C} 19)$ se referiram, respectivamente, à "atendente de enfermagem" e "cuidadora profissional”. Na literatura foram encontrados diversos artigos que falam sobre a rede pública de saúde e sua relação com as famílias de idosos com DA (Camargo, 2010; Biolo; Portella, 2010), trazendo ao cenário da discussão situações referentes à Estratégia Saúde da Família e sua função, assim como sobre a restrição da oferta de serviços da rede pública e da amplitude de sua intervenção e da falta de recursos sociais de apoio, como profissionais especializados no suporte a essas famílias.

\section{Representações de cuidadores sobre o cuidado}

A partir da análise dos resultados emergiram 4 (quatro) categorias de ECH que são as principais representações dos cuidadores familiares sobre o cuidado: cuidado como prisão; cuidado como missão; cuidado como desarmonia de identidade social; cuidado como gratidão.

Estão aqui apresentadas em ordem decrescente de intensidade e amplitude, considerando-se que quanto maior a intensidade e a amplitude de uma representação, mais essa representação identifica o grupo social a que pertence. 


\section{a. Cuidado como prisão}

(Cuidando de uma pessoa com Alzheimer) você não tem hora mais para si. Então, para você cuidar do idoso, você precisa separar, isolar a sua vida. Você não tem mais vida. Você deixa de ser dono do próprio nariz, apesar de seu eu necessitar de muita coisa. O próprio preso está lá, mas ele quer a liberdade dele. A gente fica como se o cuidador estivesse preso e não pudesse sair dali, porque tem que ficar o tempo todo controlando aquela outra pessoa. Significa que, às vezes, a gente não tem vida própria. O Alzheimer vai mexer com a vida de toda a família, principalmente com a vida daquela pessoa que vai ficar diretamente ligada. Então, eu tinha mais independência e hoje não, que hoje (a minha vida) é mais limitada. A gente sai da nossa rotina e vai fazer dentro da rotina dela. E assim, mais ou menos, a gente vai assumindo a personalidade da pessoa. Teve um momento que eu estava me sentindo até prisioneiro dentro da minha casa. Eu queria que a minha vida voltasse um pouco como era antes. Para (cuidar), tu tens que abdicar um pouco da tua vida. Eu acho muito difícil para uma pessoa abrir mão de tudo isso. A nossa vida, o dia a dia, voltou só para eles [idosos com Alzheimer]. A gente fica em função dela, com a preocupação nela. [As pessoas] não querem limitar a sua vida como a minha é limitada. [Tenho] vontade de ter liberdade, de fazer as coisas que eu fazia antes, que agora não posso mais (C2, C3, C6, C8, C10, C11, $\mathrm{C}_{13}, \mathrm{C}_{14}, \mathrm{C}_{17}, \mathrm{C}_{18}, \mathrm{C}_{20}$ ).

Em primeira análise dos resultados foram identificadas as objetivações. Segundo Jovchelovitch (2012), objetivar é condensar significados diferentes em uma realidade familiar, e ao fazer isso eles ancoram o desconhecido em uma realidade conhecida, deslocando aquela geografia de significados já estabelecida. Portanto, nessa categoria de ECH, a objetivação do cuidado está na limitação de autonomia, que aparece ancorada à ideia de prisão, a uma vida condicionada, à perda de liberdade.
Prisão é supressão de liberdade e privação de liberdade de ir e vir mediante clausura (Cunha, 2010; Capez, 2015). Quando o cuidador ancora o cuidado na ideia de prisão está comunicando que sua liberdade e autonomia estão sendo suprimidas pelo cuidado com o idoso com DA. A figura representativa do preso retrata a redução da liberdade e da autonomia de fazer o que se quer quando se quer, trazendo à vida do cuidador a rotina condicionada ao tempo requisitado pelo cuidar de um idoso com DA.

Existe no discurso coletivo de sujeitos a imagem “abdicar um pouco da própria vida”. Segundo a literatura pesquisada, a qualidade de vida é composta de valores materiais, como necessidades básicas de alimentação, trabalho, educação e valores não materiais, como liberdade, inserção social e realização pessoal (Minayo apud Zerbeto; Chun, 2013). Quando o sujeito coletivo apresenta o abandonar um pouco da própria vida para cuidar de uma pessoa com DA, demonstra que o cuidado com o idoso retira de sua vida valores que são importantes para sua satisfação pessoal, ele deixa de fazer parte da vida, deixa de ter a autonomia de ir e vir, perde a liberdade de escolha do que fazer, quando fazer, e passa a se situar à margem da vida, abandona um pouco a própria vida em prol do cuidado.

Expressões como "deixar de ser dono do próprio nariz”, “prisão", "prisioneiro”, “em função de” e "abdicar um pouco da própria vida” aparecem no discurso de $52 \%$ (n.11) dos sujeitos. A análise quantitativa dessa representação demonstra que é uma representação de grande intensidade e alta amplitude, ou seja, é fortemente compartilhada por todo o campo analisado. Essa construção do discurso é marcada pela polifonia dos sujeitos, pois são pessoas diversas compondo um discurso unificado com a força e amplitude de uma representação disseminada por todo o campo social pesquisado.

\section{b. Cuidado como missão}

Que eu fui eleita para cuidar, naturalmente caiu para mim essa responsabilidade. As circunstâncias me levaram a isso. Não é que eu me elegi a ser cuidadora. Não tinha mais ninguém (para cuidar), então eu achei que deveria tratar um 
ser humano. Se você pega um bicho na rua e trata, quanto mais um ser humano. Quem tinha a obrigação eram os filhos, eu sei que a obrigação (também) é minha (que sou filho). Eu me tornei cuidadora por exclusão, que a mulher é cuidadora por excelência. [Cuido porque] eu sou única filha, eu tenho três irmãos, os outros tiraram o corpo fora e fiquei eu. Tipo assim, ninguém quer (cuidar). Eu nem me tornei cuidadora, eu tive que ser. O natural é isso, porque nós crescemos para cuidar de quem não pode mais se cuidar. Eu sempre digo que não é uma cruz, é uma missão que Deus colocou na minha vida. [Cuido] por não haver mais ninguém, eu me sinto no direito e na obrigação de cuidar dela. Eu tive que passar a cuidar dela, porque me incumbiram. Então, como eu sou a filha, eu é que tenho a obrigação. Eu que fico com a obrigação, e como respeito para com a minha mãe ( $\mathrm{C}_{1}, \mathrm{C}_{2}, \mathrm{C}_{3}, \mathrm{C}_{4}, \mathrm{C} 6, \mathrm{C}_{7}, \mathrm{C}_{9}, \mathrm{C}_{12}$, C18, C19).

Segundo esse discurso do sujeito coletivo, o cuidado está ancorado na ideia de missão, de dever moral condicionado em parte à dignidade humana e em parte ao vinculo familiar e herança cultural. Cuidar de um parente com DA não é uma questão de escolha, é uma missão, é um encargo que foi destinado a essa cuidadora, que deve cumprir porque foi eleita para desempenhar tal papel. Torna-se cuidadora por uma necessidade de desempenhar o papel, seja pela dependência do idoso, seja pela ausência de outra pessoa para cuidar, seja pelo papel feminino na sociedade.

Expressões como "a mulher", "a filha” e "única filha" também aparecem nessa categoria de ECH para retratar a função primordialmente feminina na tarefa de cuidar: "a mulher é cuidadora por excelência" demonstra a construção histórica e cultural da sociedade, com a divisão de papéis entre homens e mulheres, onde a mulher é a enfermeira zelosa, a dona de casa, a cuidadora da família, enquanto o homem é o trabalhador, o provedor do lar e das despesas (Camargo, 2010).

Expressões como "obrigação", "missão" e "responsabilidade" aparecem em todo o discurso do sujeito coletivo trazendo o sentido de dever, de missão, até mesmo de humanidade em cuidar de uma pessoa fragilizada por uma doença progressiva e incapacitante como o Alzheimer. Condiz com o respeito à dignidade humana, que, segundo Sarlet (2007 apud Loch; Souza, 2014), é qualidade intrínseca à pessoa humana, é irrenunciável e inalienável, constituindo elemento que qualifica o ser humano e que dele não pode ser destacado. Encontra-se na fala dos cuidadores a comparação entre um animal (um bicho) e uma pessoa (o idoso com DA), que tem o direito de ter uma existência digna, que tem o direito de ser cuidado.

A representação de missão a ser cumprida, dever ou ainda obrigação de cuidar aparece em $48 \%$ (n 10) dos sujeitos e, analisando de acordo com os indicadores sociais, afirma-se que essa é uma representação de grande intensidade, pois muitas vozes contribuíram para esse discurso do sujeito coletivo, e de alta amplitude, já que as vozes estão espalhadas por todo o campo analisado.

\section{c. Cuidado como desarmonia de identidades sociais}

Tem hora que eu fico triste. Essa inversão de papéis [...], as pessoas fogem porque não entendem, não compreendem. Eu tenho um sentimento, mas ao mesmo tempo eu procuro aceitar. Teve comigo na infância, que cheguei aos braços dela exatamente como ela está agora. Nunca pensei que a mamãe pudesse chegarnesse estágio, quando ela faz as bobagens dela. $\bar{E}$ algo assim que me deixa muito preocupada e eu fico meio sem péno chão e, às vezes, sem querer acreditar. Ele se tornou uma criança. Você já imaginou uma pessoa que [...] ele, [um homem] muito trabalhador, um homem que levantava seis horas da manhã e descia e ia buscar o pão e fazia toda aquela atividade me ajudando [...], sete horas ele já estava na Kombi, lendo um jornal. De repente se torna uma pessoa inválida, uma pessoa sem identidade. Cuidar de uma pessoa com Alzheimer é um sentimento muito doído. O sentimento de que aquela pessoa perdeu a identidade, perdeu o vínculo com a família, perdeu o sentido de mãe. Então, a gente passa a cuidar dela, a ser mãe dela. A gente fica triste porque é uma pessoa que a gente ama muito, 
que cuidou a vida toda da gente e de repente se vê nessa situação. [Cuidar dela] é uma decepção muito grande. Não que seja culpa dela, naturalmente, o acaso, se é que existe acaso. [Mas] é um golpe muito grande, [porque] sempre fomos muito unidos e essa doença chegou para desestabilizar essa união. É muito difícil a situação, não só dela como da gente, que é filho, de ver a situação dela desse jeito ( $\left.\mathrm{C}_{1}, \mathrm{C}_{4}, \mathrm{C}_{7}, \mathrm{C}_{12}, \mathrm{C}_{14}, \mathrm{C}_{17}, \mathrm{C}_{18}, \mathrm{C}_{21}\right)$.

Nessa categoria de ECH, o cuidado aparece ancorado na ideia de inversão de papéis. A “Inversão de papéis" descrita pelo discurso do sujeito coletivo se refere à condição de dependência do idoso com DA em relação ao familiar cuidador, e à alteração das identidades sociais no seio familiar traz ao cuidador o sentimento de desarmonia, conflito, desestabilidade.

O papel social define-se como um padrão determinado de comportamento que reflete e caracteriza uma posição especial do indivíduo dentro do grupo social a que pertence, e tal concepção entende que o existir humano é um viver em coletividade. 0 indivíduo se realiza pelo desempenho de papéis, caráter ou função assumidos numa realidade social e cristalização final do modo de realizar ações especiais, como pai, mãe, entre outros (Martins, 2010; Rubini, 1995).

A pessoa que possui esse tipo de demência perde suas funções cognitivas gradualmente e apresenta diversas alterações comportamentais. Perde a capacidade de realizar as atividades de vida diária e até mesmo de realizar um diálogo lógico com outras pessoas (Borghi et al., 2011; Inouye; Pedrazzani; Pavarini, 2010). O idoso passa a ser comparado a uma criança pelo cuidador, deixa de ser o pai ou a mãe que cuida para se tornar o filho ou a filha que é cuidada. Tal qual uma criança, possui atitudes sem pensamento lógico de causa e consequência, dificuldades de comunicação, necessidade de ajuda para atividades simples como tomar banho e trocar de roupas e, a partir de certo ponto, necessitará de fraldas. Expressões como "criança”, "inválido", "perder o sentido de mãe" e "sem identidade", "ser mãe dela" retratam a caracterização do idoso com DA nessa relação com o cuidador. A experiência traz ao cuidador a sensação de decepção, de desarmonia por se tratar de uma doença irreversível e progressiva que retira do idoso toda a noção de seu papel de patriarca/matriarca dentro da família da qual é progenitor/progenitora.

Expressões como "sem pé no chão", "golpe”, "triste" e "desestabilizar" são imagens que remetem ao sentimento do cuidador familiar em relação à situação de dependência, perda de memória, perda de linguagem e de raciocínio lógico do seu ente querido. Não é uma doença que cause apenas uma dependência física, mas que retira do idoso sua identidade social. Por isso muitos cuidadores expressam a imagem de desarmonia e de tristeza, já que a relação emocional entre o ser cuidado e o cuidador sofreu mudanças com a doença.

A intensidade dessa representação é de 38\% (n.8), ou seja, essa é uma representação de menor força em relação às outras duas representações acima. Entretanto, possui alta amplitude por ser encontrada em diversos segmentos do campo social.

\section{d. Cuidado como gratidão}

(Cuidar é) reconhecimento de que hoje eu estou aqui porque ela decidiu me ter. $E$ tive a possibilidade de retribuir o cuidado que ela teve comigo. Então cuidar, eu diria hoje, retribuição. $\varepsilon$ gratificante./ Eu quero dar o melhor para ela retribuindo tudo que ela fez por mim, e com muito amor./ É uma questão de gratidão mesmo./ Ela (idosa) sempre me deu muito carinho, então, recebe hoje o que ela plantou. (Cuidar) é mais que uma obrigação, para mim é uma benção eu poder cuidar dela./ (Cuidar) é uma retribuição pelo que ela já cuidou de mim./ tu tens que dispor (de tempo), porque ela foi uma pessoa que a vida toda cuidou de ti./ Mas para mim é muito gratificante, eu me sinto feliz de participare cuidar da minha mãe. É para mim muito gratificante, de tudo que ela já fez por mim, para eu poder retribuir agora o que eu recebi a minha vida toda./Tem que lembrar que ela é sua mãe, ela também se sacrificou (porvocê) ( $\mathrm{C}_{4}, \mathrm{C}_{5}, \mathrm{C}_{7}$, $\mathrm{C} 9, \mathrm{C}_{10}, \mathrm{C}_{13}, \mathrm{C}_{17}, \mathrm{C}_{19}$ ). 
Esta categoria de ECH apresenta o cuidado ancorado na ideia de gratidão, retribuição e acolhe uma consequência dessa ideia, que é o sentir-se bem, o sentir-se gratificado em cuidar.

Esse discurso do sujeito coletivo retrata que cuidar de um familiar com DA é uma retribuição pelo cuidado que recebeu e que é gratificante retribuir. Expressões como "benção", "gratificante", "feliz em participar" aparecem para demonstrar a valoração que tem, para o cuidador familiar, o cuidado com uma pessoa que já fez muito por ele. Expressões como "recebe hoje o que plantou", "retribuir" aparecem como valores morais expressados pelos cuidadores familiares em uma analogia ao dever de pagar uma dívida.

A gratidão aparece no discurso do sujeito coletivo como um imperativo do dever de retribuir o carinho e dedicação que recebeu na infância. A gratificação do cuidador em cuidar é descrita por Castro et al. (2011) como uma consequência da própria gratidão, e que a diferença entre a gratidão e a obrigação é que a primeira é fonte de bem-estar, um sentimento agradável e prazeroso, enquanto que a segunda gera desprazer e mal-estar. Portanto, o cuidador se sente agraciado, sente que é "uma benção" poder saldar a dívida emocional que contraiu com o idoso; sente bem-estar em devolver aquele cuidado que recebeu na infância.

Essa representação aparece em 38\% (n8) das falas dos sujeitos, porém é encontrada apenas em falas de mulheres, na maioria católicas. A análise quantitativa dessa representação apresentou menor intensidade em relação às duas representações mais expressivas acima e baixa amplitude, ou seja, é uma representação que aparece em um segmento restrito do campo analisado.

\section{Discussão}

As representações de cuidado dos cuidadores familiares foram sintetizadas em quatro principais: prisão, missão, desarmonia de identidades sociais e gratidão. Elas podem afetar as práticas de cuidado de maneiras distintas, sendo as representações mais fortes, no grupo estudado, a limitação de autonomia (prisão) e a missão (dever moral).
Como se sabe, não é simples cuidar de outra pessoa. Existem atividades que demandam esforço físico e habilidades emocionais de quem cuida. 0 cuidador deve ter sempre paciência e disponibilidade para o cuidado, deve não se irritar com as atitudes repetitivas e a falta de lógica do idoso, deve ajudá-lo diariamente a se banhar, a se vestir, a se alimentar, deve convencê-lo de que o banho do dia ainda não foi tomado, de que ele já comeu, de que ele tem que fazer exercício e atividades para preservar a capacidade funcional, deve ser compreensivo com a agressividade e com a perda de memória do idoso, deve buscar ser empático aos sentimentos que o idoso pode estar sentindo e tentar diminuir a ansiedade, o medo, a aflição desse idoso, deve se preocupar com horários de medicações, com a fralda geriátrica, a partir de quando o idoso não consegue mais controlar as funções fisiológicas, deve se preocupar em saber se o idoso consegue dormir à noite ou se está há muito tempo deitado, pois é tendência do Alzheimer deixar o idoso mais apático e propenso a evoluir para perda de força muscular e imobilidade.

O cuidador que sente a rotina de cuidados como uma prisão tende a encarar o cuidado como uma agressão à própria vida, um desequilíbrio para a sua saúde física, psíquica e social. A pessoa que necessita de cuidados se torna um peso que tende a ser maior a casa dia até o momento em que o idoso deixar de viver. 0 cuidador acumula sentimentos negativos e conflitantes que lhe causam tensão; podem deixá-lo nervoso, irritadiço e ansioso, uma vez que se sente confinado e limitado pela necessidade de cuidar de outra pessoa.

O sentimento negativo de sentir-se preso pode afetar o cuidado que dá ao idoso, já que a insatisfação por uma atividade pode comprometer sua execução com qualidade. Acredita-se que, com esse sentimento de prisão e limitação, seria difícil o cuidador conseguir exercer um cuidado adequado, já que ele não consegue lidar com as próprias emoções, e a rotina de cuidados o faz sentir-se como um prisioneiro. Ao surgir a representação de missão na fala dos cuidadores, apresenta-se um caminho para diluir a carga emocional negativa de se sentir prisioneiro.

Nos discursos dos sujeitos, a agenda de cuidados é descrita como uma rotina rígida de tarefas, decor- 
rente da dependência do idoso em diversos aspectos. Muitos descrevem o cuidar como aprender a ser paciente, a ser tolerante, a se doar, estando de acordo com as ressonâncias de cuidar, convivialidade, compaixão e cordialidade descritas por Boff (2011).

Houve uma forte tendência de expressão de preocupação para com o ente cuidado como significado de cuidado. Para os cuidadores, o cuidado não é significante de dar atenção, de ser solícito com o ser cuidado, mas de viver num estado de preocupação constante em relação a ele, o que traz desarmonia e dificuldade de manter a medida justa do cuidado. Tal medida é uma ressonância do cuidado (Boff, 2011) baseada na percepção de que existem limites que devem ser mantidos para uma harmonia na relação do cuidador com a pessoa cuidada; o autocuidado necessário para manter o equilíbrio do cuidador em suas práticas, a percepção de que se deve estar bem para conseguir cuidar do ente dependente de forma mais harmônica. Essa ótica de medida justa para um cuidado com qualidade é encontrada em poucas falas, demonstrando a necessidade de intervenção de profissionais de saúde que os auxiliem na manutenção da estabilidade emocional necessária para o cuidar.

\section{Conclusão}

Neste estudo evidenciaram-se as representações dos cuidadores familiares de idosos com DA, demonstrando as ideias de perda de liberdade, de dever moral, de retribuição e inversão de papéis sociais presentes no contexto desses cuidadores e de seus idosos com DA.

O cuidador familiar de uma pessoa com DA muitas vezes se encontra despreparado para lidar com as situações advindas do cuidado. Toda a sua história de vida, seus desejos pessoais, seus ideais e perspectivas, suas dificuldades e conflitos são evidenciados, exacerbados, negados, esquecidos. 0 familiar precisa reaprender a lidar com o mundo e com seus idosos adoecidos e mudar suas perspectivas de vida, se readequando à situação que se lhe impõe.

A análise das repercussões das representações dos cuidadores sobre suas práticas de cuidado, por conta da metodologia adotada, foi realizada de forma indireta, a partir da análise dos discursos adquiridos na fase da coleta de dados. Acredita-se que realizar observação direta, acompanhando a rotina de cuidados desses familiares seria uma forma de contribuir para a percepção mais sólida das consequências e reflexos das representações na rotina de cuidados.

Percebeu-se entre os cuidadores sentimentos conflituosos de negação, comoção, culpa, obrigação e reclusão. A enfermagem pode atuar identificando os fatores que levam a tais sentimentos, ajudando os cuidadores a reconhecê-los e auxiliando no planejamento de alterações na rotina que possam contribuir para a diminuição da tensão emocional. Podem ainda realizar atividades educativas e encaminhamentos para apoio psicológico.

Trabalhar a relação desse cuidador com seus sentimentos e buscar capacitá-lo para novas percepções sobre o cuidado seria uma boa lógica de ação para a equipe de saúde, em especial para a enfermagem. Ideias de autodeterminação, de autogestão, de definição de limites para um cuidado de qualidade do idoso e da própria saúde devem ser exploradas pela equipe de saúde, propiciando ao cuidador a oportunidade de compreender que é preciso cuidar de si para cuidar do outro sem sentir que seja um peso ou um aprisionamento. Conquistando essa atenção, será facilitada a transformação de representações de impacto negativo sobre a qualidade de vida dos cuidadores e suas práticas de cuidado em representações que tragam maior equilíbrio à relação de cuidado entre os cuidadores familiares e seus idosos.

O Sistema de Saúde Pública (SUS), por outro lado, pode contribuir com a capacitação de cuidadores familiares e profissionais e a organização de serviços efetivos, atuantes e preparados para atender às necessidades desses cuidadores, fornecendo uma rede de suporte adequado às necessidades das famílias.

\section{Referências}

ADI - ALZHEIMER'S DISEASE INTERNATIONAL. World Alzheimer Report 2015: the global impact of dementia - an analysis of prevalence, incidence, cost and trends. London, 2015. Disponível 
em: <http://www.alz.co.uk/research/worldreport-2015>. Acesso em: 29 ago. 2015

BIOLO, H. F.; PORTELLA, M. R. Vivência do cuidador familiar: casos acompanhados pela estratégia de saúde da família na cidade de Passo Fundo - RS.

Estudos Interdisciplinares sobre o Envelhecimento, Porto Alegre, v. 15, n. 2, p. 177-195, 2010.

BIONDI, M. J. R. Alzheimer: o outro lado, a visão do cuidador. São Paulo: Phoenix, 2009.

BOFF, L. Saber cuidar: ética do humano compaixão pela terra. 19. ed. Petrópolis: Vozes, 2011.

BORGHI, A. C. et al. Qualidade de vida de idosos com doença de Alzheimer e de seus cuidadores. Revista Gaúcha de Enfermagem, Porto Alegre, v. 32, n. 4, p. 751-758, 2011.

BRASIL. Resolução 466, de 12 de dezembro de 2012. Aprova diretrizes e normas regulamentadoras de pesquisas envolvendo seres humanos. Diário Oficial [da] República Federativa do Brasil, Brasília, DF, 13 jun. 2013. Seção 1, p. 59.

CAMARGO, R. C. V. F. Implicações na saúde mental de cuidadores de idosos: uma necessidade urgente de apoio formal. SMAD, Ribeirão Preto, v. 6, n. 2, p.231-254, 2010.

CAPEZ, F. Curso de processo penal. 22. ed. São Paulo: Saraiva, 2015.

CASTRO, F. M. P. et al. Deve-se retribuir? Gratidão e dívida simbólica na infância. Estudos de

Psicologia, n. 16, v. 1, p. 75-82, 2011. Disponível em: <http://www.scielo.br/pdf/epsic/v16n1/a1ov16n1. pdf $>$. Acesso em: 31 out. 2013.

COSTA, J. L.; MOURÃO, V.; GONÇALVES, M. D. O impacto da "vulnerabilidade extrema" dos doentes nos seus cuidadores principais: Uma perspectiva multidimensional. Revista Kairós Gerontologia, n. 17, v. 1, p. 27-43, São Paulo (SP), março, 2014. Disponível em: <http://revistas.pucsp.br/index. php/kairos/article/view/19656/14528>. Acesso em: 30 ago. 2015 .

CUNHA, A. G. da. Dicionário etimológico da língua portuguesa. Rio de Janeiro: Lexikon, 2010.

FERREIRA, A. B. H. Dicionário Aurélio da Língua Portuguesa. 5. ed. Curitiba: Positivo, 2010.
FIGUEIREDO, N. M. A. de; TONINI, T. (Org.) Gerontologia: atuação da enfermagem no processo de envelhecimento. São Caetano do Sul: YENDIS, 2010.

FREITAS, R. V. Diagnóstico precoce na doença de Alzheimer utilizando biomarcadores e tomografia PET CT. 2015. Trabalho de Conclusão de Curso (Graduação em Biomedicina) - Faculdade de Ciências da Educação e Saúde, Centro Universitário de Brasília, Brasília, DF, 2015. Disponível em: <http://www.repositorio.uniceub. br/bitstream/235/6868/1/21234951.pdf >. Acesso em: 3 set. 2015 .

INOUYE, K.; PEDRAZZANI, E. S.; PAVARINI, S. C. I. Implicações da doença de Alzheimer na qualidade de vida do cuidador: um estudo comparativo. Cadernos de Saúde Pública, Rio de Janeiro, n. 26, v. 5, p. 891-899, 2010.

IBGE - INSTITUTO BRASILEIRO DE GEOGRAFIA E ESTATÍSTICA. Síntese de indicadores sociais: uma análise das condições de vida da população brasileira. Brasília, DF, 2010. (Série Estudos e pesquisas. Número 27.). Disponível em: <http://www.ibge.gov.br/home/estatistica/ populacao/condicaodevida/indicadoresminimos/ sinteseindicsociais2010/SIS_2010.pdf >. Acesso em: 10 ago. 2013.

JOVCHELOVITCH, S. Vivendo a vida com os outros: intersubjetividade, espaço público e representações sociais. In: GUARECHI, P. A.; JOVCHELOVITCH, S. Textos em representações sociais. 13. ed. Petrópolis: Vozes, 2012.

LEFÈVRE, F.; LEFÈVRE, A. M. Pesquisa de representação social: um enfoque qualiquantitativo. 2. ed. Brasília, DF: Liber Livro, 2012.

LOCH, J. A; SOUZA, P. V. S; Bioética na Atualidade. Porto Alegre: EDIPUC, 2014.

MARTINS, E. S. Os papéis sociais na formação do cenário social e da identidade. Kínesis, v. 2, n. 4, p. 40-52, São Paulo, 2010. Disponível em: <http://www.marilia.unesp. br/Home/RevistasEletronicas/Kinesis/ Ospapeissociaisnaformacao.pdf $>$. Acesso em: 5 set. 2015. 
MOSCOVICI, S. Representações Sociais: investigações em psicologia social. 9. ed.

Petrópolis, Vozes, 2011.

OPAS - ORGANIZACIÓN PANAMERICANA DE LA

SALUD. Demencia: una prioridad de salud pública. Washington, DC, 2013.

PRINCE, M.; GUERCHET, M.; PRINA, M. Policy brief for heads of government: the global impact of dementia 2013-2050. London: Alzheimer's Diases International, 2013. Disponível em: <https://www. alz.co.uk/research/GlobalImpactDementiazo13. pdf $>$. Acesso em: 30 dez. 2013.

RUBINI, C. O conceito de papel no psicodrama. Revista Brasileira de Psicodrama, v. 3, n.1, p. 45-62, São Paulo, 1995. Disponível em: < http:// pesquisa.bvs.br/brasil/resource/pt/psi-3053>. Acesso em: 31 out. 2013.

SANTOS, F. da S; JÚNIOR, J. L. O idoso e o processo de envelhecimento: um estudo sobre a qualidade de vida na terceira idade. Revista de Psicologia, v.8, n. 24, p. 34-55, nov. 2014. Disponível em: <http://idonline.emnuvens.com.br/id/article/ view/300>. Acesso em: 30 ago. 2015.
SEGURO, A. de O. et al. O cuidar: a dimensão de uma palavra que tem como significado uma profissão. Revista Rede de Cuidados em Saúde, Duque de Caxias (RJ), v. 2, n. 2, p.1-14, 2008. Disponível em: <http://publicacoes.unigranrio.edu.br/index.php/ rcs/article/viewFile/9o/99>. Acesso em: 12 mar. 2013.

XIMENES, M. A.; RICO, B. L. D.; PEDREIRA, R. Q. Doença de Alzheimer: a dependência e o cuidado. Revista Kairós Gerontologia, São Paulo, n. 17, v. 2, p. 121-140, 2014.

WHO - World Health Organization. Dementia cases set to triple by 2050 but still largely ignored. Geneva, 2012. Disponível em: <http:// www.who.int/mediacentre/news/releases/2012/ dementia_20120411/en/>. Acesso em: 13 out. 2013.

ZERBETO, A. B.; CHUN, R. Y. S. Qualidade de vida dos cuidadores de crianças e adolescentes com alterações de fala e linguagem. CoDAS, São Paulo, n. 25, v. 2, p. 128-134, 2013. Disponível em: <http:// www.scielo.br/pdf/codas/v25n2/ao7v25n2.pdf>. Acesso em: 3 set. 2015.

\section{Contribuição dos autores}

Cinthia Filgueira Maciel Mendes foi responsável pela concepção e revisão do artigo. Anderson Lineu Siqueira dos Santos fez a revisão bibliográfica e orientou o trabalho.

\section{Agradecimentos}

Agradeço ao professor Anderson Lineu Siqueira dos Santos pela orientação, críticas e sugestões, e ao grupo de apoio da ABRAz-Pará pela disponibilidade e apoio que fizeram este trabalho possível.

Recebido: 07/11/2014

Reapresentado: 25/08/2015

Aprovado: 21/09/2015 